Dhaka Univ. J. Sci. 60(1): 79-85, 2012 (January)

\title{
Application of a Mathematical Model by Means of Experimental Design to Alkylation of $o$-Cresol with Cyclohexene
}

\author{
Mohammad Kamruzzaman*, Ashequl Alam Rana, Md. Zahangir Alam and Manoranjan Saha \\ Department of Applied Chemistry and Chemical Engineering, University of Dhaka, Dhaka-1000, Bangladesh
}

Received on 29.03.2011. Accepted for Publication on 20.08.2011

\begin{abstract}
Alkylation of $o$-cresol with cyclohexene in the presence of perchloric acid as catalyst was studied statistically with a three-factored experimental design. Factorial design was employed to study the effects of single factors and the effects of their interactions on the yield of alkylation. Reaction temperature, molar ratio of $o$-cresol to cyclohexene and amount of perchloric acid were considered as the major variables. A mathematical model was derived to calculate the predicted yield of alkylation of $o$-cresol with cyclohexene in the presence of perchloric acid under certain reaction conditions and cyclohexyl $o$-cresol was obtained in high yield. The adequacy of the suggested model was checked up and the discrepancies between the experimental and calculated values did not exceed $1.52 \%$. An optimum yield $(89.5 \%)$ of the product was obtained under the reaction conditions of a temperature of $140^{\circ} \mathrm{C}$; a $6: 1$ molar ratio of $o$ cresol to cyclohexene and a $5 \%$ by weight perchloric acid of $o$-cresol.
\end{abstract}

Keywords: Alkylation, $o$-Cresol, Factorial design.

\section{Introduction}

The alkylation of aromatic substrates is important in many sectors of the chemical industry. Alkylation of cresols has earned much interest of the scientists since alkylated cresols may be used as raw materials for the production of resins, durable surface coatings, varnishes, printing inks, surface active agents, antioxidants, fungicides, petroleum additives, and multifunctional stabilizers for fuels, lubricating oils and polymeric materials ${ }^{1-6}$. Catalytic alkylation of isomeric cresols with different alcohols and esters have been studied by several research groups ${ }^{7-16}$. Reports are also available on the alkylation of isomeric cresols with olefins and styrene in presence of different catalysts ${ }^{17-22}$, while alkylation of $o$ cresol with alkenes especially cyclohexene was not studied so much. With the best of our knowledge only alkylation of $o-, m$-, and $p$ - cresols with cyclohexene in the presence of aluminum cresolates have been studied ${ }^{23}$. We envisioned to studying this classical reaction statistically with the help of experimental design.

The concept of experimental design in synthetic chemistry is very much important to develop a new method, to improve an existing method or to avoid highly expensive experiments. Many books and reviews have been published on experimental design in chemometrics ${ }^{24-28}$. Experimental design is used to synthesize a product in an efficient way. The objectives are first to understand the effect of factors and their interactions and then to form a relationship between response and factors with a minimum number of experiments. Responses are dependent variables while factors are independent ones. In most cases, responses and factors are denoted by $y$ and $x\left(x_{1}, x_{2}, \ldots x_{s}\right)$, respectively, and $y=f\left(x_{1}, x_{2}, \ldots x_{s}\right)$ where, $s$ is the number of factors.
Choosing suitable quantitative factors such as temperature, time, and $\mathrm{pH}$ is very important in synthetic chemistry. There are several profile analysis procedures available for estimating main effects of factors and their interaction effects, and so on ${ }^{29,30}$.

In this study, the three-factor two-level Yates Pattern experimental design is used for the analysis of alkylation of $o$-cresol with cyclohexene in presence of perchloric acid ${ }^{31}$.

\section{Experimental}

Chemicals used in this work were purchased from Merck Chemicals Co. and were used without further purification unless stated. Perchloric acid was used as catalyst.

The reactions were carried out in a three necked round bottomed flask fitted with a condenser, a thermometer, a dropping funnel and a stirrer. $o$-Cresol-catalyst mixture was charged into the flask, heated to the temperature of the experiment, the cyclohexene was introduced into the mixture gradually over a certain period of time (time of addition) with constant stirring. The reaction mixture was stirred for another period of time (time of stirring) at the same temperature after the addition of the total amount of cyclohexene. The reaction mass was then cooled to room temperature and neutralized with an equivalent amount of $10 \% \mathrm{KOH}$ solution. The neutralized reaction mass was then dissolved in benzene or diethyl ether, washed with distilled water several times and dried with anhydrous magnesium sulfate. Unreacted reactants and solvent were distilled off at atmospheric pressure. The product thus obtained was subjected to fractionation by distillation and characterized by physico-chemical and spectral means. A statistical analysis of yields of the experiments was performed to develop a mathematical model.

\footnotetext{
*Corresponding Author Tel.: +880-2-9661920-73/7400; Fax: +880-2-8615583
}

E-mail: mkzamandu@gmail.com 


\section{Results and Discussion}

$o$-Cresol with cyclohexene in the presence of perchloric acid as catalyst gave cyclohexyl $o$-cresol (cyclohexyl group substituted the aromatic ring to the ortho- or para-positions with respect to the $-\mathrm{OH}$ group).

A series of experiments were designed for alkylation of $o$ cresol with cyclohexene in presence of perchloric acid. The design table helped in setting the factors in the experimental runs and calculation of the effects (Yates). In the alkylation of $o$-cresol with cyclohexene temperature, molar ratio of $o$ cresol to cyclohexene and amount of catalyst were considered as the three variables, which were supposed to influence the yield significantly. Obviously, there are some other variables in this experiment such as time of addition, time of stirring, stirring speed, etc. These variables were not included as factors, and they are kept constant at a certain value during the experiment. The various values at which a factor is tested are called levels. The experimental ranges of the variables are listed in Table 1 . The yield of product was considered as the critical response of the experimental design.
Table 1. Experimental variables and their levels.

\begin{tabular}{|l|c|c|c|}
\hline \multicolumn{1}{|c|}{ Variable } & \multicolumn{3}{|c|}{ Range } \\
\cline { 2 - 4 } & Low (-) & Mid (0) & High (+) \\
\hline$x_{1} ;$ Temperature & 60 & 100 & 140 \\
$\left({ }^{\circ} \mathrm{C}\right)$ & $5: 1$ & $6: 1$ \\
$x_{2} ;$ M olar ratio of $o-$ \\
cresol to cyclohexene \\
$x_{3}$; A mount of catalyst, \\
$\%$ by wt. of $o$-cresol & 1 & 3 & 5 \\
\hline \multicolumn{2}{|l|}{ Response: y-yield of cyclohexyl $o$-cresol } \\
\hline
\end{tabular}

Table 2 illustrates the two-level 3-factor design with the factors in coded form. The experimental runs for trials 1-8 were run in duplicate; trial 9 , the center point trial was run four times, interspersed throughout the experimental runs.

Table 2. Experimental design.

\begin{tabular}{|c|c|c|c|c|}
\hline \multirow{2}{*}{ Trial } & \multirow{2}{*}{ Replicates } & \multicolumn{3}{|c|}{ Design } \\
\cline { 3 - 5 } & & Temperature, $x_{1}$ & $\begin{array}{c}\text { Molar ratio of } o \text {-cresol to } \\
\text { cyclohexene, } x_{2}\end{array}$ & $\begin{array}{c}\text { Amount of catalyst, \% } \\
\text { by wt. of } o \text {-cresol, } x_{3}\end{array}$ \\
\hline 1 & 2 & - & - \\
2 & 2 & + & - & - \\
3 & 2 & - & + & - \\
4 & 2 & + & - & + \\
5 & 2 & - & - & + \\
6 & 2 & + & + & + \\
7 & 2 & + & + & 0 \\
\hline & 2 & + & 0 & + \\
\hline
\end{tabular}

The results of the experiments of alkylation of $o$-cresol with cyclohexene in presence of perchloric acid are listed in Table 3 . 
Table 3. Results of three-factor experiment

\begin{tabular}{|c|c|c|c|c|c|}
\hline \multirow[t]{2}{*}{ Trial } & \multicolumn{3}{|c|}{ Yield } & \multirow[t]{2}{*}{ Range } & \multirow[t]{2}{*}{ Variance } \\
\hline & $y_{1}$ & $y_{2}$ & $\bar{y}$ & & \\
\hline 1 & 40.6 & 41.8 & 41.2 & 1 & 0.72 \\
\hline 2 & 60.4 & 62.0 & 61.2 & 2 & 1.28 \\
\hline 3 & 46.9 & 48.7 & 47.8 & 2 & 1.62 \\
\hline 4 & 73.3 & 75.5 & 74.4 & 2 & 2.42 \\
\hline 5 & 44.1 & 45.5 & 44.8 & 1 & 0.98 \\
\hline 6 & 67.4 & 69.8 & 68.6 & 2 & 2.88 \\
\hline 7 & 66.3 & 68.5 & 67.4 & 2 & 2.42 \\
\hline \multirow[t]{2}{*}{8} & 88.2 & 90.8 & 89.5 & 3 & 3.38 \\
\hline & & & & & \\
\hline \multirow[t]{2}{*}{9} & & & 60.9 & 2 & 1.05 \\
\hline & 60.3 & 62.0 & & & \\
\hline
\end{tabular}

The average yield, $\bar{y}$ for each trial, the range and the variance were calculated for each trial. The variance, which is an estimate of dispersion of data was calculated by the following formula ${ }^{32}$ and summarized in Table 3.

$$
\begin{aligned}
& \left(\mathrm{y}_{1}-\bar{y}\right)^{2}+\left(y_{2}-\bar{y}\right)^{2}+\ldots . \\
& \text { Variance }=S^{2}=\frac{\ldots \ldots+\left(y_{n}+\bar{y}\right)^{2}}{n-1} \\
& 0.72+1.28+1.62+2.42+0.98+2.88+2.42 \\
& =+3.38+3.15 \\
& =\frac{1+1+1+1+1+1+1+1+3}{1+38} \\
& =\frac{18.85}{11}=1.71363
\end{aligned}
$$

where, $y=$ response value, $\bar{y}=$ average or mean response values and $n=$ number of observations.

The variances calculated for each trial with Eq. (1) were then used in the calculation of a weighted average of the individual variances for each trial.

Pooled variance was calculated by the following equation:

Pooled variance $=S_{\text {pooled }}^{2}$

$=\frac{\left(n_{1}-1\right)\left(S_{1}^{2}\right)+\left(n_{2}-1\right)\left(S_{2}^{2}\right)+\ldots .+\left(n_{k}-1\right)\left(S_{k}^{2}\right)}{\left(n_{1}-1\right)+\left(n_{2}-1\right)+\ldots . .+\left(n_{k}-1\right)}$
According to definition, pooled standard deviation is the square root of pooled variance. Therefore:

$=$ Standard deviation $_{\text {pooled }}=\sqrt{S_{\text {Pooled }}^{2}}$

The pooled standard deviation was used to calculate the minimum observed effects that were statistically significant.

Table 4 illustrates the two-level three-factor designs with the factors in coded form. 
Table 4. Computational matrix for three-factor experiments.

\begin{tabular}{|c|c|c|c|c|c|c|c|c|c|}
\hline \multirow{2}{*}{ Trial } & \multirow{2}{*}{ Mean } & \multicolumn{3}{|c|}{ Design } & \multicolumn{4}{|c|}{ Computation } & \multirow{2}{*}{$\frac{\text { Response }}{\bar{y}}$} \\
\hline & & $x_{1}$ & $x_{2}$ & $x_{3}$ & $x_{12}$ & $x_{13}$ & $x_{23}$ & $x_{123}$ & \\
\hline 1 & + & - & - & - & + & + & + & - & 41.2 \\
\hline 2 & + & + & - & - & - & - & + & + & 61.2 \\
\hline 3 & + & - & + & - & - & + & - & + & 47.8 \\
\hline 4 & + & + & + & - & + & - & - & - & 74.4 \\
\hline 5 & + & - & - & + & + & - & - & + & 44.8 \\
\hline 6 & + & + & - & + & - & + & - & - & 68.6 \\
\hline 7 & + & - & + & + & - & - & + & - & 67.4 \\
\hline 8 & + & + & + & + & + & + & + & + & 89.5 \\
\hline Sum +'s & 494.9 & 293.7 & 279.1 & 270.3 & 249.9 & 247.1 & 259.3 & 243.3 & \\
\hline Sum -'s & 0 & 201.2 & 215.8 & 224.6 & 245.0 & 247.8 & 235.6 & 251.6 & \\
\hline Sum & 494.9 & 494.9 & 494.9 & 494.9 & 494.9 & 494.9 & 494.9 & 494.9 & \\
\hline Difference & 494.9 & 92.5 & 63.3 & 45.7 & 4.9 & -0.7 & 23.7 & -8.3 & \\
\hline Effect & 61.86 & $23.12 *$ & $15.82 *$ & $11.42 *$ & 1.22 & -0.17 & $5.92 *$ & $-2.07 *$ & \\
\hline
\end{tabular}

The experimental design used was Yates pattern, threefactor two-level factorial; therefore, there were $2^{3}$, i.e. eight trials. Since the basic $2^{3}$ factorial design involved eight trials, each was run in duplicate yielding 16 trials. In order to check the lack of fit due to curvature, additional trial was made at the midpoint level of each factor. The difference between the average centre point value and the overall average of the design points indicated the severity of curvature. The computation analysis for this experiment is also shown in Table 4. According to definition, a main effect is the difference between the average response at the high level and the average response at the low level of a factor. Using the design Table 4, the effects of the factors are calculated as sum of the product between the sign of the corresponding factor in the design matrix and the response, divided by $N / 2$. The design matrix was supplemented with a computation matrix, which was used to detect any interaction effects. This computation matrix was generated by simple algebraic multiplication of the coded factor levels. The column at the far right of the table was the average yield for each trial. The sum +'s was calculated by the summation of the response values on each row with a plus sign for each column. In the similar manner the sum -'s was calculated. The sum of +'s and -'s should be equal for all factors and interactions and was used to check the calculations and design. The difference row represented the difference between the responses in the four trials when the factor was at a high level and that at a low level. The effect was then calculated by dividing the difference with the number of plus signs in the column. In the first column of Table 4, labeled mean, the effect was the mean of all data points. The average of the centre point runs, Trial 9, was then subtracted from mean effect to give a measure of curvature.

The minimum significant factor effect $[\mathrm{MIN}]$ and the minimum significant curvature effect [MINC] were again 
derived from $t$-test significance criteria according to the following equations:

$$
\begin{aligned}
& {[M I N]=t . s \sqrt{\frac{2}{m \cdot k}}} \\
& {[M I N C]=t . s \sqrt{\frac{1}{m \cdot k}+\frac{1}{c}}}
\end{aligned}
$$

where $t=$ appropriate value from "t table", $s=$ pooled standard deviation, $m=$ number of plus signs in column, $k=$ number of replicates in each trial and $c=$ number of center points.

The $t$ value of 2.20 was taken from the students" "t" table for the $95 \%$ confidence level and 11 degrees of freedom ${ }^{32}$.

The degree of freedom resulted from eight trials with two replicates and one trial with four replicates.

Degrees of freedom $=8(2-1)+1(4-1)=11$.

By substituting the values in Eqs. (3) and (4) we have

$$
\begin{aligned}
& {[M I N]=2.20 \times 1.30905 \sqrt{\frac{2}{4 \times 2}}=1.4399} \\
& {[M I N C]=2.20 \times 1.30905 \sqrt{\frac{1}{8 \times 2}+\frac{1}{4}}=1.6099}
\end{aligned}
$$

By comparing the [MIN] and [MINC] values and effects calculated by experimental design (Table 4) the significant factors and the interaction effects of the factors that influence the yields were determined. It was revealed that the effects of temperature $\left(x_{1}\right)$, molar ratio of $o$-cresol to cyclohexene $\left(x_{2}\right)$, amount of perchloric acid $\left(x_{3}\right)$, interaction between molar ratio of $o$-cresol to cyclohexene and amount of perchloric acid $\left(x_{23}\right)$, and temperature, molar ratio of $o$ cresol to cyclohexene and amount of perchloric acid $\left(x_{123}\right)$ were significant. There was no significant curvature effect. These results can be expressed as a mathematical model using a first order polynomial. The values for the coefficients are one half of the factor effects listed in the Table 4 , since these are based on coded levels +1 and -1 that differed by two units. Therefore, the following mathematical model in which factors are in the coded form can be developed:

$$
\begin{aligned}
& y=61.86+11.56 x_{1}+7.91 x_{2}+5.71 x_{3}+2.96 x_{2} x_{3} \\
& -1.04 x_{1} x_{2} x_{3}
\end{aligned}
$$

The coded units in Eq. (5) can be converted into real units by substituting their values.

For temperature,

$$
\begin{gathered}
x_{1}=\frac{T\left({ }^{0} C\right)-\frac{140+60}{2}}{\frac{140-60}{2}}=\frac{T\left({ }^{0} C\right)-100}{40} \\
\text { For molar ratio, } x_{2}=\frac{m-\frac{6+4}{2}}{\frac{6-4}{2}}=\frac{m-5}{1}
\end{gathered}
$$

For amount of catalyst,

$$
x_{3}=\frac{w-\frac{5+1}{2}}{\frac{5-1}{2}}=\frac{w-3}{2}
$$

where, $T=$ temperature $\left({ }^{\circ} \mathrm{C}\right) ; m=$ molar ratio of $o$-cresol to cyclohexene and $w=$ amount of perchloric acid, \% by wt. of $o$-cresol.

The substitutions of $x_{1}, x_{2}, x_{3}, x_{23}$, and $x_{123}$ values in Eq. (5) yield the final mathematical model:

$$
\begin{aligned}
y= & 61.86+11.56\left(\frac{T-100}{40}\right)+7.91\left(\frac{m-5}{1}\right) \\
& +5.71\left(\frac{w-3}{2}\right)+2.96\left(\frac{m-5}{1}\right)\left(\frac{w-3}{2}\right) \\
& -1.04\left(\frac{T-100}{40}\right)\left(\frac{m-5}{1}\right)\left(\frac{w-3}{2}\right) \\
y=26.54+ & 0.094 T-0.43 m-11.04 w+0.039 T m \\
+ & 2.78 m w+0.065 T w-0.013 T m w
\end{aligned}
$$

For Trial 1, yield calculated from the derived model

$$
\begin{aligned}
& y_{(\text {calculated })}=26.54+0.094 \times 60-0.43 \times 4 \\
& \quad-11.04 \times 1+0.039 \times 60 \times 4+2.78 \times 4 \times 1 \\
& +0.065 \times 60 \times 1-0.013 \times 60 \times 4 \times 1 . \\
& =40.68 .
\end{aligned}
$$

Table 5 summarizes the experimental and predicted yields of alkylation of $o$-cresol with cyclohexene in presence of perchloric acid under various experimental conditions.

The experimental yield and calculated yield showed a good agreement. Thus the application of statistical design provided a convenient set of experimental conditions for the synthesis of cyclohexyl $o$-cresol.

The UV spectrum of cyclohexyl $o$-cresol showed strong absorption at $\lambda_{\text {max. }}=296.0 \mathrm{~nm}$ in $0.01 \mathrm{M}$ petroleum ether solution. 
Table 5. Alkylation of o-cresol with cyclohexene in the presence of perchloric acid undervarious reaction conditions.

\begin{tabular}{|c|c|c|c|c|c|c|}
\hline Trial & $\begin{array}{c}\text { Te m p. } \\
\left({ }^{\mathrm{o}} \mathrm{C}\right)\end{array}$ & $\begin{array}{l}\text { Molar ratio of } \\
o \text {-cresol to } \\
\text { cyclohexene }\end{array}$ & $\begin{array}{l}\text { A mount of } \\
\text { catalyst, } \% \text { by } \\
\text { wt. of } o \text {-cresol }\end{array}$ & $\begin{array}{c}\text { Experim ental } \\
\text { yield }(\%)\end{array}$ & $\begin{array}{l}\text { Calculated } \\
\text { yield }(\%)\end{array}$ & $\begin{array}{l}\text { Percent } \\
\text { deviation }\end{array}$ \\
\hline 1 & 60 & $4: 1$ & 1 & 41.2 & 40.68 & 1.26 \\
\hline 2 & 140 & $4: 1$ & 1 & 61.2 & 61.72 & 0.85 \\
\hline 3 & 60 & $6: 1$ & 1 & 47.8 & 48.50 & 1.46 \\
\hline 4 & 140 & $6: 1$ & 1 & 74.4 & 73.70 & 0.94 \\
\hline 5 & 60 & $4: 1$ & 5 & 44.8 & 44.12 & 1.52 \\
\hline 6 & 140 & $4: 1$ & 5 & 68.6 & 69.32 & 1.05 \\
\hline 7 & 60 & $6: 1$ & 5 & 67.4 & 67.94 & 0.80 \\
\hline 8 & 140 & $6: 1$ & 5 & 89.5 & 88.98 & 0.58 \\
\hline
\end{tabular}

In the IR spectrum, absorption band at $775 \mathrm{~cm}^{-1}$ accounted for 1,2,3-trisubstituted aromatic ring, while bands near 805 $\mathrm{cm}^{-1}$ and $855 \mathrm{~cm}^{-1}$ indicated the presence of 1,2,4trisubstituted benzene ring. Band at $3400 \mathrm{~cm}^{-1}$ indicated the presence of $-\mathrm{OH}$ group. Aromatic $\mathrm{C}_{\ldots . . \mathrm{C}}$ stretch and saturated C-H stretch were observed at $1570 \mathrm{~cm}^{-1}$ and 2850 $2910 \mathrm{~cm}^{-1}$ respectively.

The ${ }^{1} \mathrm{H}$ NMR-spectrum of cyclohexyl $o$-cresol showed signal at $\delta=6.26-7.1 \mathrm{ppm}$ for aromatic ring protons. Signals for $-\mathrm{OH}$ group proton, methyl group protons, all the protons on the cyclohexyl group except one on the $\alpha$-position relative to the aromatic ring and one proton on the $\alpha$ position were observed at $\delta=4.84 \mathrm{ppm}, \delta=2.03-2.33 \mathrm{ppm}$, $\delta=0.94-2.03 \mathrm{ppm}$ and $\delta=2.33-3.23$ respectively.

Cyclohexyl $o$-cresol had b.p. $=297^{\circ} \mathrm{C}, \mathrm{d}_{4}{ }^{20}=1.0418$ and $\mathrm{n}_{\mathrm{D}}{ }^{20}=1.5459$.

\section{Conclusion}

The yield of alkylation of $o$-cresol with cyclohexene in the presence of perchloric acid was optimized by means of experimental design. Results of this study indicated that all the three variables, e.g. temperature, molar ratio of $o$-cresol to cyclohexene and amount of perchloric acid, and interactions between molar ratio of $o$-cresol to cyclohexene and amount of perchloric acid $\left(x_{23}\right)$, and temperature, molar ratio of $o$-cresol to cyclohexene and amount of perchloric acid $\left(x_{123}\right)$ significantly affect the response (yield). The predicted yield calculated with the derived mathematical model showed a good agreement with the experimental yield and the discrepancies between the experimental and calculated values did not exceed $1.52 \%$. Thus the mathematical model obtained provided a convenient set of experimental conditions for the production of cyclohexyl $o$ cresol and open up for efficient strategies for experimental studies.

1. Lebedev, N.N., 1984. Chemistry and Technology of Basic Organic and Petrochemical Synthesis. Vols. I and II, Mir Publishers, Moscow.

2. Subramanian, S., A. Mitra, C.V.V. Satyanarayana and D.K. Chakrabarty, 1997. Para-selective butylation of phenol over silicoaluminophosphate molecular sieve SAPO-11 catalyst. Appl. Catal. A: Gen. 159, 229-240.

3. Sakthivel, A., S.K. Badamali and P. Selvam, 2000. Selective para-t-butylation of phenol over mesoporous H-AlMCM-41. Micropor. Mesopor. Mater. 39, 457-463.

4. Sato, T., G. Sekiguchi, T. Adschiri and K. Arai, 2001. Noncatalytic and selective alkylation of phenol with propan-2-ol in supercritical water. Chem. Commun. 17, 1566.

5. Zhang, K., H. Zhang, G. Xu, S. Xiang, D. Xu, S. Liu and H. $\mathrm{Li}$, 2001. Alkylation of phenol with tert-butyl alcohol catalyzed by large pore zeolites. Appl. Catal. A: Gen. 207, 183-190.

6. Krishnan, A.V., K. Ojha and N.C. Pradhan, 2002. Alkylation of phenol with tertiary butyl alcohol over zeolites. Org. Proc. Res. Dev. 6(2), 132 -137. 
7. Basak, P.K., S.K. Saha, M. Ashaduzzaman and M. Saha, 2004. Alkylation of cresols with tert-amyl alcohol. Dhaka Univ. J. Sci. 52(3), 287-292.

8. Grabowska, H., L. Syper and M. Zawadzki, 2004. Vapour phase alkylation of ortho-, meta- and para-cresols with isopropyl alcohol in the presence of sol-gel prepared alumina catalyst. Appl. Catal. A: Gen. 277(1-2), 91-97.

9. Yadav, G.D. and G.S. Pathre, 2006. Novel meso porous solid superacids for selective C-alkylation of $m$-cresol with tertbutanol. Micropor. Mesopor.Mater. 89(1-3), 16-24.

10. Saha, M., P.K. Basak, S.K. Saha and M. Ashaduzzaman, 2001. Alkylation of $m$-cresol with cycloalcohols in the presence of sulfuric acid. Bangladesh J. Sci. Ind. Res. 36(14), 109-114.

11. Grabowska, H. and J. Wrzyszcz, 2001. C-alkylation of $m$ cresol with $n$ - and iso-propanol over iron catalyst. Res. Chem. Intermediates. 27(3), 281-285.

12. Velu, S. and S. Sivasankar, 1998. Alkylation of $m$-cresol with methanol and 2-propanol over calcined magnesium-aluminum hydrotalcites. Res. Chem. Intermediates. 24(6), 657-666.

13. Saha, M. and R.K. Roy, 1992. Alkylation of $m$-cresol with cyclohexanol in the presence of sulphuric acid. Bangladesh $J$. Sci. Ind. Res. 27(3-4), 23-29.

14. Shanmugapriya, K., M. Palanichamy, V.V. Balasubramanian and V. Murugesan, 2006. Vapour phase reaction of $m$-cresol and ethyl acetate over MCM-41 molecular sieves: One-pot synthesis of coumarin derivatives. Micropor. Mesopor. Mater. 95 (1-3), 272-278.

15. Devassy, B.M., G.V. Shanbhag, F. Lefebvre and S.B. Halligudi, 2004. Alkylation of $p$-cresol with tert-butanol catalyzed by heteropoly acid supported on zirconia catalyst. $J$. Mol. Catal. A: Chem. 210, 125-130.

16. Yadav, G.D., A.A. Pujari and A.V. Joshi, 1999. Alkylation of $p$-cresol with methyl tert-butyl ether (MTBE) over a novel solid acid catalyst UDCaT-1. Green Chem. 1(6), 269-274.

17. Chaudhuri, B., A.A. Patwardhan and M.M. Sharma, 1990. Alkylation of substituted phenols with olefins and separation of close-boiling phenolic substances via alkylation/dealkylation. Ind. Eng. Chem. Res. 29(6), 10251031.

18. Saha, M., S. Chowdhury, M.A.B. Sarker, Y.N. Jolly and D. Saha, 1997. A study of alkylation of cresols with cyclooctene. Bangladesh J. Sci. Ind. Res. 32(1), 63-66.
19. Sadykhov, I.Sh., V.P. Yaskin, Sh.G. Sadykhov, T.N. Mashkova, M.A. Gasanov, S.A. Prokhorova and K.K. Aktasheva, 1996. Reaction of methylphenols with alkyl- and alkenylcycloalkenes. Neftekhimiya. 36(4), 362-365.

20. Kozlikovskii, Ya.B., B.V. Chernyaev, A.L. Litvin and A.V. Kofanova, 1986. Reaction of $o_{-}^{-,} m-$, and $p$-cresol with styrene in the presence of aluminum cresoxides. Zhurnal Organicheskoi Khimii. 22(7), 1469-1474.

21. Trocsanyi, Z., 1975. Alkylphenol type of antioxidants, I. The alkylation of $p$ - and $m$-cresol with isobutylene. Magyar Asvanyolaj- es Foldgazkiserleti Intezet Kozlemenyei. 16, 119129.

22. Yadav, G.D. and R. Pala, 2000. Selectivity engineering in the $\mathrm{O}$ - versus C-alkylation of $p$-cresol with cyclohexene over sulfated zirconia. Can. J. Chem. Eng. 78(5), 917-927.

23. Kozlikovskii, Ya.B., V.A. Koshchii, S.A. Butov and A.V. Sokolova, 1987. Ortho alkylation of $o-, m-$, and $p$-cresols with cyclohexene in the presence of aluminum cresolates. Zhurnal Organicheskoi Khimii. 23(9), 1918-1924.

24. Deming, S.N. and S.L. Morgan, 1993. Experimental Design: A Chemometric Approach, 2nd ed., Elsevier, Amsterdam.

25. Carlson, R., 1982. Design and Optimisation in Organic Synthesis, Elsevier, Amsterdam.

26. Goupy, J.L., 1993. Methods for Experimental Design, Principles and Applications for Physicists and Chemists, Elsevier, Amsterdam.

27. Atkinson, A.C. and A.N. Donev, 1992. Optimum Experimental Designs, Clarendon Press, Oxford.

28. Grize, Y.L., 1995. A review of robust process design approaches. J. Chemom. 9, 239-262.

29. Box, G.E.P., W.G. Hunter and J.S. Hunter, 1978. Statistics for Experiments; An Introduction to Design, Data Analysis and Model Building, Wiley, New York.

30. Morgan, E.D., 1995. Chemometrics: Experimental Design, Wiley, New York.

31. Clausen, C.A. and G. Matson, 1978. Principles of Industrial Chemistry, Wiley Interscience Publication, New York, p. 412.

32. Davies, O.L., 1979. Design and Analysis of Industrial Experiments, 2nd ed., Longman, London, p. 636. 